\title{
Pineal cysts: an incidental MRI finding?
}

\author{
A Di Costanzo, G Tedeschi, F Di Salle, F Golia, R Morrone, V Bonavita
}

\begin{abstract}
The incidence of pineal cysts (PC) in "standard" MRI was reviewed. Seven cases of PC were found from 400 consecutive MRI examinations. PC did not produce clinically relevant symptoms in any of the patients. Our data, as well as those emerging from a critical review of the literature, suggest that PC are often asymptomatic and represent an incidental MRI finding.
\end{abstract}

(F Neurol Neurosurg Psychiatry 1993;56:207-208)

Pineal cysts (PC) are a common finding at necropsy. ${ }^{1-3}$ Nevertheless; since the cyst fluid can have density similar to CSF, PC can escape detection on CT examination of the brain and be confused with the quadrigeminal cistern. ${ }^{4}$

Since the introduction of MRI, PC have been identified more frequently and considered as a normal variant without clinical relevance. $^{4-6}$

Recently, however, Klein and Rubinstein ${ }^{7}$ in a clinicopathological study reported seven cases of symptomatic PC from 1500 consecutive examinations. We reviewed 400 consecutive brain MRIs and evaluated the clinical relevance of PC in the seven cases identified.

\section{Material and methods}

MRIs were carried out with a $0.5 \mathrm{~T} \mathrm{GE}$ system. The images were obtained by $\mathrm{T} 1$ weighted sequences (Spin Echo 500/20, Fast Scan $500 / 90 / 15)$ in the sagittal plane: proton density

University of Naples,

Naples, Italy

Institute of

Neurological Sciences,

First School of

Medicine

A Di Costanzo

G Tedeschi

V Bonavita

Institute of

Radiological Sciences

Second School of

Medicine

F Di Salle

F Golia

R Morrone

Correspondence to:

Dr Tedeschi, Institute of

Neurological Sciences, First

School of Medicine,

University of Naples, Via

Pansini 5, 80131 Naples,

Italy.

Received 18 December 1991

and in revised form

17 February 1992.

Accepted 24 February 1992 echo 2000/35-120) on the frontal plane; T1 weighted (inversion recovery 1350-1500/ 400/20) and T2 weighted (fast scan $500 / 23 / 28-30$ ) in the axial plane. Section thickness was $5 \mathrm{~mm}$ with a $2 \mathrm{~mm}$ gap in the sagittal plane and $7 \mathrm{~mm}$ with a $3 \mathrm{~mm}$ gap in the frontal and axial planes.

The seven patients with MRI signs of PC had clinical examination.

\section{Results}

Clinical and MRI findings of the seven selected patients are reported in the table.

No patient had symptoms and/or signs of an expansive lesion in the pineal region. Patient 1 , affected by retrobulbar neuritis, was studied by MRI three times over a period of 18 months, and no variation in dimension and signal characteristics of PC were found.

PC had a maximum diameter of 5-15 mm, and a thin wall $(\leq 2 \mathrm{~mm})$ with smooth margins. The cystic content appeared homogeneous and compared with CSF, isointense or slightly hyperintense in T1-weighted images and hyperintense in proton density and moderately T2-weighted images. PCs were best detected by sagittal $T 1$ weighted images, which gave a good assessment of pineal morphology and regional anatomy (figure).

\section{Discussion}

In necropsy cases, mostly small cysts have been reported in $20-40 \%$ of normal pineal glands. ${ }^{2}{ }^{3}$

In none of our patients was the PC resected and histologically examined, nevertheless their
Table Clinical characteristics and MRI findings in the seven patients with pineal cysts (PC)

\begin{tabular}{|c|c|c|c|c|c|c|}
\hline Patient & Age (yrs) & Sex & Symptoms & Diagnosis & Maximum diameter of $P C$ & Other MRI findings \\
\hline 1 & 20 & $\mathbf{F}$ & $\begin{array}{l}\text { Loss of visual acuity in } \\
\text { left eye }\end{array}$ & $\begin{array}{l}\text { Retrobulbar optic } \\
\text { neuritis }\end{array}$ & $10 \mathrm{~mm}$ & None \\
\hline 2 & 70 & $\mathbf{M}$ & $\begin{array}{l}\text { Mental deterioration, } \\
\text { hemiparesis }\end{array}$ & Multi-infarct dementia & $15 \mathrm{~mm}$ & \multirow{2}{*}{$\begin{array}{l}\text { Cortical cerebral } \\
\text { atrophy, multiple } \\
\text { white matter lesions } \\
\text { None }\end{array}$} \\
\hline 3 & 54 & $\mathbf{F}$ & $\begin{array}{l}\text { Headache, mood } \\
\text { depression, anxiety }\end{array}$ & Tension-type headache & $12 \mathrm{~mm}$ & \\
\hline 4 & 25 & $\mathbf{M}$ & $\begin{array}{l}\text { Tonic clonic generalised } \\
\text { seizures }\end{array}$ & Epilepsy & $5 \mathrm{~mm}$ & None \\
\hline 5 & 9 & $\mathbf{F}$ & Absence seizures & Epilepsy & $13 \mathrm{~mm}$ & $\begin{array}{l}\text { Frontal lobes atrophy, } \\
\text { white matter } \\
\text { alteration }\end{array}$ \\
\hline 6 & 16 & F & $\begin{array}{l}\text { Severe mental } \\
\text { retardation }\end{array}$ & $\begin{array}{l}\text { Neonatal } \\
\text { encephalopathy }\end{array}$ & $8 \mathrm{~mm}$ & $\begin{array}{l}\text { Right frontal and } \\
\text { parietal lobes atrophy, } \\
\text { white matter } \\
\text { alteration }\end{array}$ \\
\hline 7 & 29 & $\mathbf{F}$ & Complex partial seizures & Epilepsy & $9 \mathrm{~mm}$ & None \\
\hline
\end{tabular}




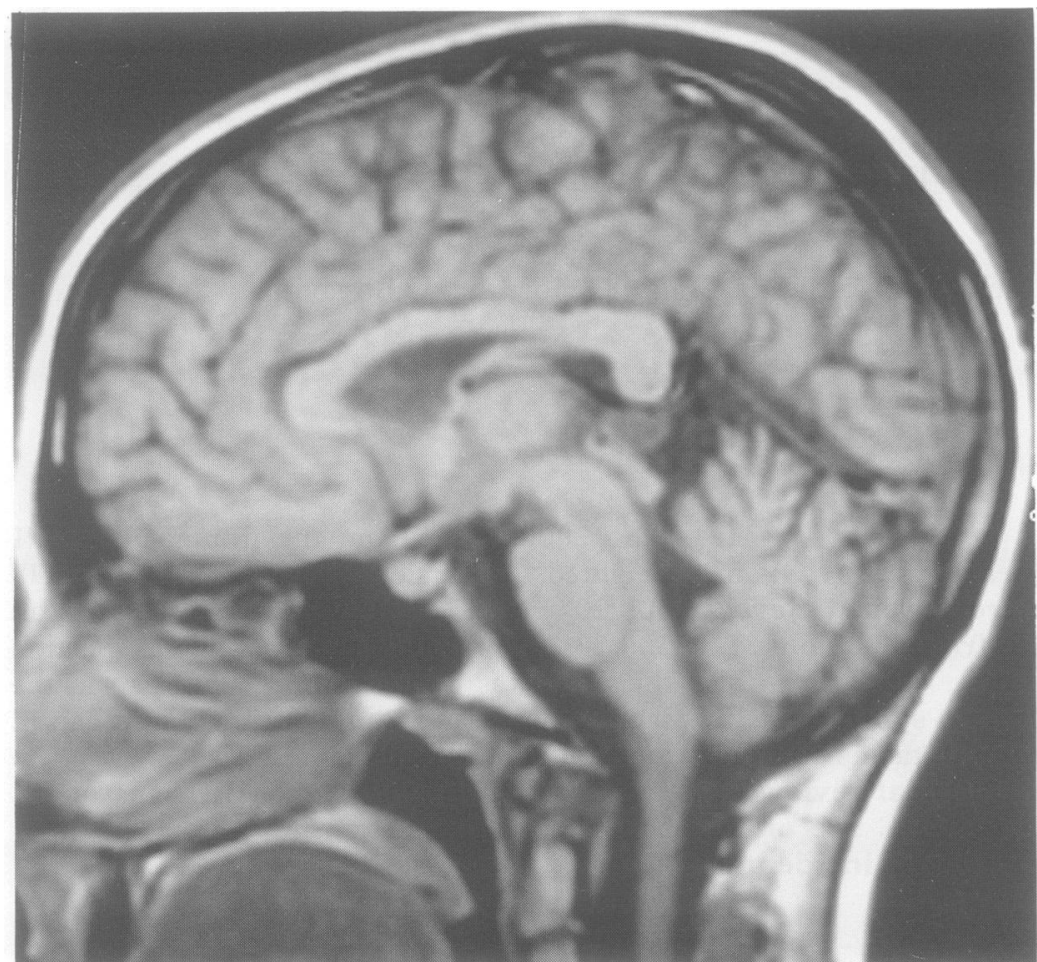

Figure Typical MRI appearance of a pineal cyst on T1-weighted sagittal images.

MRI characteristics overlapped with those described by other authors who carried out pathological examinations. ${ }^{5} 7$

The incidence of PCs found in our study (7 cases of $400 \mathrm{MRIs}$ ) agrees with the one reported by Lee et $a^{5}$ in a retrospective study. In a prospective study, Mamourian and Towfighi ${ }^{4}$ reported a considerably high incidence (29 cases of $678 \mathrm{MRIs}$ ). Their specific imaging study of the pineal region, is likely to have been more sensitive. However, the incidence reported was lower than has been found at necropsy which means that most PCs are below the resolution of current routine imaging techniques.

In agreement with previous reports ${ }^{4-6}$, PCs observed in our seven patients were a purely incidental finding, without any clinical expres- sion. Moreover, the absence of damage in the three successive MRI examinations of patient 1 , suggests an unchanging condition. Lee et $a l^{5}$ repeated MRI examinations after twelve months in one patient and, as in our case, ruled out an evoluting lesion damage.

From a review of the literature, it appears that cases of symptomatic PC have been overemphasised. Of the seven cases reported by Klein and Rubinstein, ${ }^{7}$ only three showed symptoms and/or signs which could be related to an expansive process of the pineal region. In their two cases with headache, the lack of clinical details does not establish a clear relation between headache and PC. In their 12 year old patient, the acute onset of symptoms with headache, photophobia, asthenia, dysarthria, peripheral deficit of the right facial nerve, incoordination of the left hand and impaired walking, does not seem to be related to the PC found at CT ( $1 \mathrm{~cm}$ diameter). In their other patient with positional headache, "slight visual disturbances" and negative neurological examination, it is possible that the $\mathrm{PC}$, in particular positions of the head, compressed the vein of Galen and/or the aqueduct of Sylvius, causing headache. Nevertheless, the patients with compression of the vein of Galen and quadrigeminal lamina, reported by Mamourian and Towfighi, ${ }^{4}$ were completely asymptomatic.

We conclude that PCs are almost always asymptomatic and represent an incidental MRI finding.

1 Arieti S. The pineal gland in old age. $f$ Neuropathol Exp Neurol 1954;13:482-9.

2 Tapp E, Huxley M. The istological appearance of the human pineal gland from puberty to old age. $\mathcal{f}$ Pathol 1972; 108:137-144.

3 Hasegawa A, Ohtsubo K, Mori W. Pineal gland in old age; quantitative and qualitative morphological study of 168 human autopsy cases. Brain Res 1987;409:343-9

4 Mamourian AC, Towfighi J. Pineal Cysts: Magnetic Resonance Imaging. AЭNR 1986;71081-6.

5 Lee DH, Norman D, Newton TH. Magnetic resonance imaging of pineal cysts. $\mathcal{f}$ Comput Assist Tomogr 1987, 11:586-90.

6 Sandhu JS, McLaughlin JR, Gomez CR. Characteristics of incidental pineal cysts on Magnetic Resonance Imaging. Neurosurgery 1989;25:636-40.

7 Klein P, Rubinstein LJ. Benign symptomatic glial cysts of the pineal gland: a report of seven cases and review of the literature. $\mathcal{F}$ Neurol Neurosurg Psychiatry 1989;52:991-5. 